\title{
Distribution Pattern of HCV Genotype and Its Association with Liver Functioning Enzymes and Viral Load
}

\author{
Apeksha Lahiri ${ }^{1}$, Nasifa Hasan ${ }^{2}$, Soma Chowdhury ${ }^{2}$,Saheli Podder ${ }^{2}$, \\ Sudip Roy ${ }^{2}$, Arpita Ghosh ${ }^{2}$ \\ ${ }^{1}$ (Department of Microbiology, St. Xavier's college(autonomous),Kolkata, India) \\ ${ }^{2}$ (HLA \& Molecular Laboratory, Medica Superspeciality Hospital,Kolkata, India)
}

\begin{abstract}
:
Background and objectives: Hepatitis C virus (HCV) causes chronic infectious disease called hepatitis $C$ that mainly affects the liver by scaring the liver tissues which ultimately leads to cirrhosis and hepatocellular carcinoma. The viral load and genotyping of the virus was done from patients sample and the functionality of the various liver enzymes was tested by biochemical approaches.

Methods: Twenty-nine HCV RNA positive patients were studied. RNA was exacted and quantified and genotyped by RT PCR. Total bilirubin, S.G.O.T, S.G.P.T, total protein, and alkaline phosphatase were analyzed by biochemical approaches.
\end{abstract}

Result: $53.57 \%$ are genotype 1, $24.13 \%$ are genotype 3 and $20.68 \%$ are other than genotype 1, 2, 3, 4. The SGOT level in genotype 1 showed significant difference with reference to standard deviation and mean.

Interpretation: The present study revealed that $\mathrm{HCV}$ genotype 1 accounted for $53.57 \%$ and have the $\mathrm{HCV}$ infection in Kolkata and surrounding areas.

Keywords: biochemical analysis, chronic liver disease, genotype, $H C V$, viral load

\section{Introduction}

Chronic liver diseases are mainly due to Hepatitis $\mathrm{C}$ virus, which further leads to cirrhosis of liver with increased risk of hepatocellular carcinoma. ${ }^{[1]}$ Radiological testing, biochemical analysis and routine serological examination mostly discover chronic hepatitis $\mathrm{C}$.

There are still many aspects to be discovered related to the natural history and progression of hepatitis $\mathrm{C}$ virus. The various factors that are important in predicting the outcome of disease progression include age of infection, genotype/subtype, gender of the patient, mode of infection and viral load. ${ }^{[2]}$ Standard clinical and biochemical techniques help to monitor the rate progression from chronic hepatitis leading to cirrhosis and hepatocellular carcinoma. Histology is mainly used in assessing severity of the disease and its progression. ${ }^{[3]}$ Polymerase chain reaction (PCR) advancement allows the identification and quantification of HCV RNA from serum but its clinical role remains unclear. A relationship can be drawn out between HCV type, subtype and serum HCV RNA levels. ${ }^{[4]}$ The relationship between the biochemical markers of inflammation alanine transaminase (ALT), serum HCV RNA levels by RT- PCR and histological degree of inflammation shows conflicting reports. ${ }^{[5]}$ The reason behind this may be the heterogeneity of the patients studied, which includes ethnic origin, mixed age and gender, ill-defined duration of disease and mixed HCV genotypes and subtypes. AST is normally found in a diversity of tissues including liver, heart, muscle, kidney, and brain. It is released into serum when any one of these tissues is damaged. For example, its level in serum rises with heart attacks and with muscle disorders. It is therefore not a highly specific indicator of liver injury. ALT is a very specific and well defined indicator of liver status during chronic diseases because ALT is most concentrated in the liver and is released in the bloodstream. ${ }^{[6]}$ In case of bilirubin on the other hand during cirrhosis and viral hepatitis the level of enzyme is reduced due deficiency in metabolism (e.g., reduced hepatocyte uptake, impaired conjugation of bilirubin, and reduced hepatocyte secretion of bilirubin). The present study is mainly based on the distribution pattern of HCV genotypes in patients with chronic hepatitis and is linked with their biochemical profile and viral load.

\subsection{Patients}

\section{Materials and Methods}

The data was collected for 29 patients over the year 2010-2014 who was either admitted or was attended by Medica Superspecilality Hospital in Kolkata.

\subsection{Inclusion criterion}

Patients with high viral load whose genotyping was done. 


\subsection{RNA extraction}

The blood samples in EDTA vials were collected. The artus HCV RG RT-PCR kit that constitutes of a ready-to-use system for the detection of HCV RNA was used. ${ }^{[7]}$

\subsection{Quantitative analysis of RNA}

PCR on Rotor-Gene Q instruments was done. 30 $\mu$ l of Master mix was pipetted into each PCR tube and $20 \mu 1$ of eluted sample RNA was added to it. $20 \mu l$ of the quantitation standards (HCV RG) as positive control and $20 \mu \mathrm{l}$ of water as negative control were taken in separate tubes. The Hold temperature at $50^{\circ} \mathrm{C}$ is kept for 30 mins.If the Hold temperature is at $95^{\circ} \mathrm{C}$ then it is kept for $15 \mathrm{mins}$ Cycling (cycle repeats 50 times) at $95^{\circ} \mathrm{C}$ for 30secs, $50^{\circ} \mathrm{C}$ for 60 secs and at $72^{\circ} \mathrm{C}$ for 30 secs Reverse transcription of the RNA takes place by initial activation of the hot start enzyme. Then amplification of the cDNA takes place. The fluorescence sensitivity is adjusted and the run is done.

\subsection{HCV genotype analysis}

HCV Genotype Plus Real-TM is used which is a Real-Time PCR test for the determination of HCVRNA genotypes 1a, 1b, 2, 3, 4, 5a and 6 in the human plasma. $0.2 \mu 1$ ready to use PCR tubes are there were the extracted viral RNA can be added. ${ }^{[8]}$ The kit consists of primers and probes conserved to 5' UTR region of HCV genome. Exogenous internal control RNA was used to check the extraction and amplification.

\subsection{Total Bilirubin analysis}

VITROS TBIL slide method and VITROS chemistry products calibrator kit 4 was used on VITROS 250/ VITROS 5.1/FS integrated system. The specimen was centrifuged after it had clotted to prevent hemolysis. The VITROS slides are dry, multilayered analytical elements coated on polyester supports. $10 \mu \mathrm{l}$ of patient sample was deposited onto the slide and evenly distributed to all of the layers. The spreading layer contains the appropriate substrate and other components needed for the reaction ${ }^{[9]}$. Dyphylline $0.5 \mathrm{mg}$ and $4-(\mathrm{N}-$ carboxymethylaminosulfonyl) Benzene diazonium hexafluorophosphate $57 \mu \mathrm{g}$ were added to measure the total bilirubin at a absorption maxima of 540 and $460 \mathrm{~nm} \cdot{ }^{[10]}$

\subsection{S.G.P.T analysis}

VITROS ALT slides method and VITROS chemistry products calibrator kit 3 was used. Unhaemolysed patients serum was diluted with $7 \%$ VITROS BSA and reanalyzed ${ }^{[11]}$ The results are multiplied by the dilution factor to obtain an estimate of the original sample's alanine aminotransferase activity. Lactate dehydrogenase $0.12 \mathrm{U}$, L-alanine $0.86 \mathrm{mg}$, sodium $\alpha$-ketoglutarate $54 \mu \mathrm{g}$, nicotinamide adenine dinucleotide( reduced ) $35 \mu \mathrm{g}$; and sodium pyridoxal-5- phosphate $11 \mu \mathrm{g}$ are the reagents added to the $11 \mu \mathrm{l}$ patients sample .$^{[12]}$.The rate of oxidation of NADH was monitored by reflectance spectrophotometry at $340 \mathrm{~nm}$. The rate of change in reflection density is proportional to enzyme activity.

\subsection{S.G.O.T analysis}

VITROS AST slides method and VITROS chemistry products calibrator kit 3 was used. Unhaemolysed patients serum was diluted with $7 \%$ VITROS BSA and reanalyzed. ${ }^{[13]}$ The results are multiplied by the dilution factor to obtain an estimate of the original sample's amino aminotransferase activity. Other than the main reagents enzyme cofactors, pigment, binders, buffer, surfactants, stabilizer, scavenger, dye solubilizer, filter dyes and cross-linking agents are used. ${ }^{[14]}$. The rate of oxidation of the leuco dye was monitored by reflectance spectrophotometry at $670 \mathrm{~nm}$..

\subsection{Total protein analysis}

The VITROS TP Slide method is performed using the VITROS TP Slides and the VITROS Chemistry Products Calibrator Kit 4 on VITROS 250/ VITROS 5.1/FS integrated system. The specimen should be centrifuged and the patients serum should be separated from the cell material..$^{15]}$ Copper sulfate $0.9 \mathrm{mg}$; tartaric acid $1.2 \mathrm{mg}$; and lithium hydroxide $1.3 \mathrm{mg}$ are mixed with $10 \mu \mathrm{l}$ of sample. ${ }^{[16]}$ The other reagents used are polymer beads, binders and surfactants. The VITROS TP Slide is a multilayered, analytical element coated on a polyester support. The method of analysis is based on the biuret reaction, ${ }^{[17]}$ which produces a violet complex when protein reacts with cupric ion $(\mathrm{Cu}+2)$ in an alkaline medium.

\subsection{Alkaline phosphatase analysis}

The VITROS ALKP Slide method is performed using the VITROS ALKP Slides and the VITROS Chemistry Products Calibrator Kit 3 on VITROS 250/ VITROS 5.1/FS integrated system. Unhaemolysed patient's serum is used. The specimen needs to be centrifuged and the serum has to be separated from the cell materials. p-nitrophenyl phosphate $55 \mu \mathrm{g}$; 2-amino-2-methyl-1-propanol (AMP) $0.1 \mathrm{mg}$; and magnesium sulfate 
$1.6 \mu \mathrm{g}$ are mixed with $11 \mu \mathrm{l}$ of sample. ${ }^{[18]}$ The mixture is monitored by reflectance spectrophotometry at $400 \mathrm{~nm}$.

\section{Result}

From TABLE 1 we can infer that infection due to genotype 1 is more prevalent and the percentage of genotype three and others are almost same. Both by TABLE 1 and Fig 1 it is evident that the number of indivisuals getting affected by genotype 1 is much more. The relation between HCV genotypes and serum glutamic pyruvic transaminase (SGPT), serum glutamic oxaloacetic transaminase (SGOT), total protein, total bilrubin, and alkaline phosphatase was studied None of these biochemical parameters except SGOT showed significant difference between the mean and standard deviation in genotype one. The difference between the others genotype were not well understood and need further mathematical analysis.

Table 1:percentage of each genotype among all patients

\begin{tabular}{|l|l|}
\hline Genotype & Count (\%) \\
\hline Genotype -1 & $53.57 \%$ \\
\hline Genotype-3 & $24.13 \%$ \\
\hline Other than Genotype 1,2,3,4 & $20.68 \%$ \\
\hline
\end{tabular}
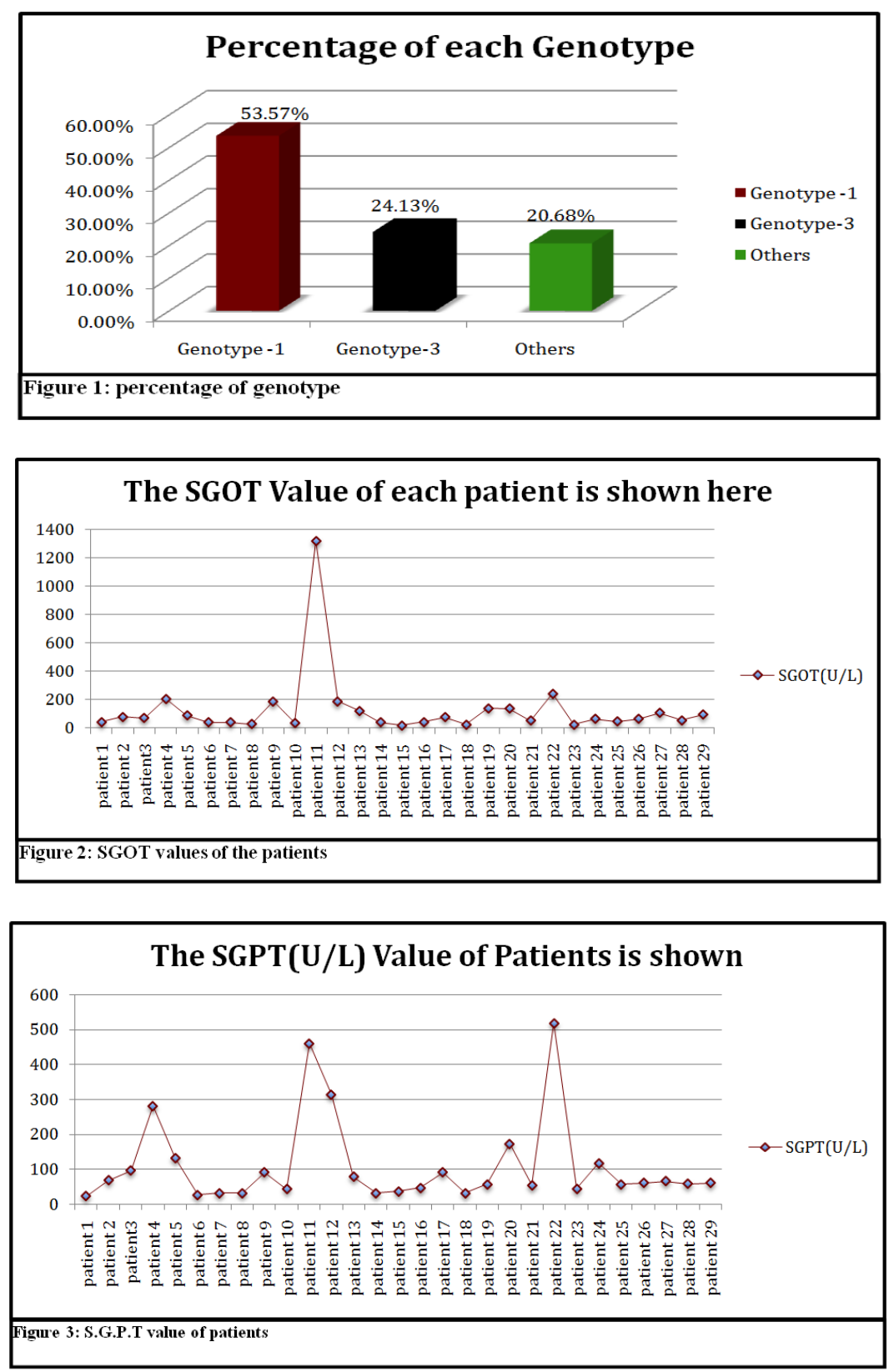

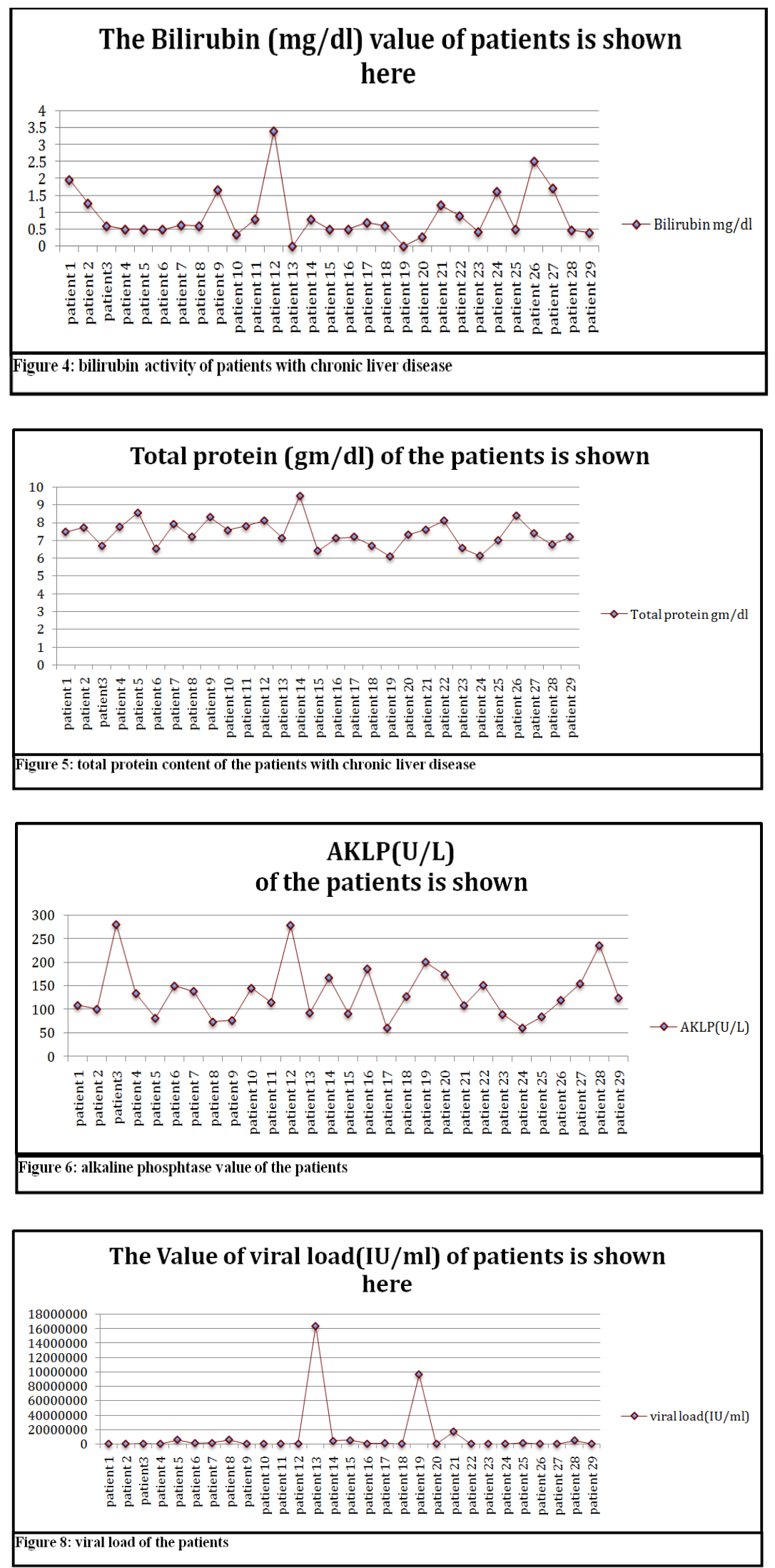


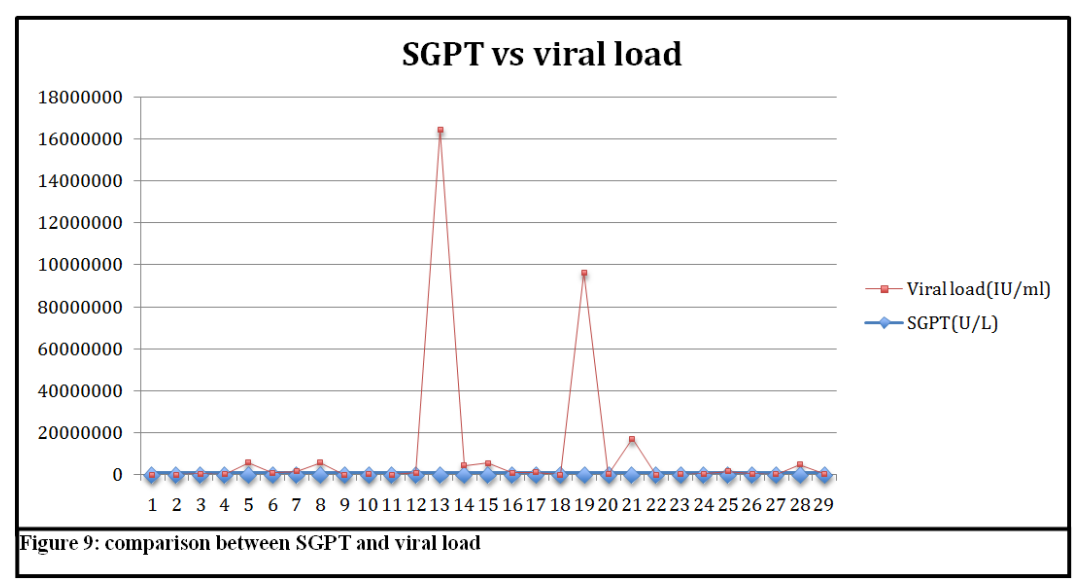

Table 2:the biochemical profile and viral load of patients is shown here

\begin{tabular}{|c|c|c|c|c|c|c|}
\hline Genotype & $\begin{array}{l}\text { Viral load } \\
\text { (IU/ml) }\end{array}$ & SGPT (U/L) & SGOT (U/L) & $\begin{array}{l}\text { TBLB } \\
\text { (mg/dl) }\end{array}$ & TP (gm./dl) & $\operatorname{ALKP}(\mathbf{U} / \mathbf{L})$ \\
\hline Genotype-1 & $1.9 * 10^{5} \pm 4.61 * 10^{6}$ & $134.21 \pm 102.55$ & $196.47 \pm 118.48$ & $0.99 \pm 0.88$ & $6.598 \pm 0.66$ & $149.8 \pm 59.69$ \\
\hline Genotype-3 & $4.7 * 10^{5} \pm 5.7 * 10^{5}$ & $91.7 \pm 85$ & $80.4 \pm 61.93$ & $0.95 \pm 0.503$ & $7.40 \pm 1.61$ & $112.42 \pm 50.12$ \\
\hline $\begin{array}{l}\text { Other than } \\
1,2,3,4 \\
\text { Mean and SD } \\
\text { are done }\end{array}$ & $1.17 * 10^{6} \pm 1.67 * 10^{6}$ & $64.1 \pm 34.27$ & $75 \pm 57.07$ & $1.077 \pm 0.826$ & $7.821 \pm 0.58$ & $121.6 \pm 35.08$ \\
\hline
\end{tabular}

\section{Discussion}

Hepatitis $\mathrm{C}$ virus (HCV) is RNA-containing, hepatotropic virus belonging to the Flaviviridae family. Contamination with hepatitis $\mathrm{C}$ virus occurs at direct entering of the virus in blood (at parenteral interventions or during blood transfusions). Most people with acute HCV infection are asymptomatic or have mild symptoms (fatigue, nausea, jaundice) but they are unable to clear the virus and in approximately $80 \%$ of cases this leads to chronic infection. In 15 to $20 \%$ of patients chronic $\mathrm{HCV}$ infection progresses at a variable rate to cirrhosis, with a 1 to $4 \%$ annual risk of developing hepatocellular carcinoma. ${ }^{[8]} \mathrm{HCV}$ is transmitted primarily through the parenteral route and source of infection include injection, drug abuse, needle stick accidents and transfusion of blood and its bi- products. Dentists practicing oral surgery, practitioners of folk medicine and those involved in hairdressing and tattooing are also at higher risk for HCV ${ }^{[19]}$ Infections in North America, Latin America and Europe are mainly due to genotype $1 .{ }^{[20]}$ North Africa and middle east have high prevalence of G4.the Asia pacific region is predominantly infected by genotype one followed by genotype $3 .{ }^{[20]}$ Genotype two is present in most developed countries ${ }^{[21][19]}$, but is less common than genotype 1 . In this study however genotype 1 was found to be dominant in Kolkata and its surrounding areas (53.57\%) followed by genotype 3(24.13\%) and other than genotype 1, 2, 3, 4 (20.68\%).

Viral load did not affect the liver enzymes SGOT and SGPT as shown in Fig 9 and 10. Even though the viral load fluctuated amongst individuals the value of enzymes did not fluctuate accordingly. Even for high viral loads the amount of enzymes remained approximately similar. From Fig 2 in case of patient eleven we can see that even if the SGOT level was the highest the viral load was low (Fig 8). There appears to be no significant correlation between HCV RNA levels and ALT values or histological activity in patients untreated by anti-viral therapies (Interferon). Viral load varies between infected individuals but is not a useful prognostic indicator nor does it measure the severity of virus-induced liver disease. ${ }^{[22]}$

An initial step in detecting liver damage is a simple blood test to determine the presence of certain liver enzymes in the blood. Under normal circumstances, these enzymes reside within the cells of the liver. But when the liver is injured, these enzymes are spilled into the blood stream. Among the most sensitive and widely used of these liver enzymes are the aminotransferases. They include aspartate aminotransferase (AST or SGOT) and alanine aminotransferase (ALT or SGPT). These enzymes are normally contained within liver cells. If the liver is injured, the liver cells spill the enzymes into blood, raising the enzyme levels in the blood and signaling the liver damage. AST (SGOT) is normally found in a diversity of tissues including liver, heart, muscle, kidney, and brain. It is released into serum when any one of these tissues is damaged. For example, its level in serum rises with heart attacks and with muscle disorders. It is therefore not a highly specific indicator of liver injury. ALT (SGPT) is, by contrast, normally found largely in the liver. This is not to say that it is exclusively located in liver but that is where it is most concentrated. It is released into the bloodstream as the result of liver injury. It therefore serves as a fairly specific indicator of liver status. In this study SGOT was significantly different according to its standard deviation and mean in genotype 1 (TABLE 2). All other biochemical parameters were 
deranged but changes remained non significant as also reported earlier ${ }^{[23] .}$

\section{Conclusion}

Liver infections due to HCV genotype 1 was most prevalent in Kolkata and the surrounding areas followed by genotype 3. Care should be taken to prevent infections by HCV genotype 1 without ignoring genotype 3 and other prevailing genotypes.

\section{Acknowledgment}

We wish to acknowledge Medica Superspeciality Hospital, Kolkata, for providing us the opportunity to work on this. We would also extend our gratitude to Lab director, Dr. D.K Pahari, for giving us permission to conduct this study. We also take the opportunity to thank Department of Microbiology St. Xavier's college for their cooperation.

[1] Seeff LB, Hollinger FB, Alter HJ, Wright EC, Cain CM, Buskell ZJ, et al. Long-term mortality and morbidity of transfusionassociated non-A, non-B, and type C hepatitis: A National Heart, Lung, and Blood Institute collaborative study. Hepatology. 2001;33:455-63. [PubMed: 11172349]

[2] Berry V, Arora R, Paul P. Hepatitis C-Clinical outcome and diagnosis. J K Sci. 2005;7:129-32.

[3] Guido M, Fagiuoli S, Tessari G, Burra P, Leandro G, Boccagni P, et al. Histology predicts cirrhotic evolution of post transplant hepatitis C. Gut. 2002;50:697-700. [PMCID: PMC1773206] [PubMed: 11950819]

[4] Bimpson A, MacLean A, Cameron S, Carman W. Replacing HCV antibody testing with detection by real time PCR. J Clin Virol. 2006;36(Suppl. 3):S32-9.

[5] Fanning L, Kenny E, Sheehan M, Cannon B, Whelton M, O'Connell J. Viral load and clinicopathological features of chronic hepatitis C (1b) in a homogeneous patient population. Hepatology. 1999;29:904-7. [PubMed: 10051496]

[6] Strader DB, Wright T, Thomas DL, Seeff LB. Diagnosis, management, and treatment of hepatitis C. Hepatology. 2004;39:1147-71. [PubMed: 15057920]

[7] Automated extraction of viral-pathogen RNA and DNA for high-throughput quantitative real-time PCR, Beuselinck K, van Ranst M, and van Eldere J, J. Clin. Microbial. 2005 Nov; 43: 5541-5546

[8] Sacace biotechnologies catalogue 2014

[9] Test Methodology, VITROS Chemistry Products. August 1997, Johnson \& Johnson Clinical Diagnostics, Inc.

[10] VITROS Chemistry Products TBIL Slides, version 5.0, Ortho-Clinical Diagnostics Johnson \& Johnson .[Pub. No. MP2-39_EN]

[11] Young DS. Effects of Preanalytical Variables on Clinical Laboratory Tests. Washington D.C.: AACC Press; $3-7$; 1993.

[12] VITROS Chemistry Products ALT Slides, version 5.0, Ortho-Clinical Diagnostics Johnson \& Johnson [ Pub. No. MP2-36 EN]

[13] Young DS. Effects of Preanalytical Variables on Clinical Laboratory Tests. ed. 2. Washington D.C.: AACC Press; 3 -69, 3-70; 1997.

[14] VITROS Chemistry Products AST Slides, version 6.0, Ortho-Clinical Diagnostics Johnson \& Johnson [ Pub. No. MP2-113_EN]

[15] Clinical Laboratory Handbook for Patient Preparation and Specimen Handling, Fascicle VI: Chemistry/Clinical Microscopy. (Northfield,IL: College of American Pathologists; 1992).

[16] VITROS Chemistry Products TP Slides, version 3.0, Ortho-Clinical Diagnostics Johnson \& Johnson[Pub. No. MP2-18_EN]

[17] Kingsley GR. The Direct Biuret Method for Determination of Serum Proteins as Applied to Photoelectric and Visual Colorimetry. (J. Lab.Clin. Med. 27:840.845; 1942).

[18] VITROS Chemistry Products ALKP Slides, version 4.0, Ortho-Clinical Diagnostics Johnson \& Johnson [Pub. No. MP2-37_EN]

[19] Anita Chakravarti, Gaurav Dogra, Vikas Verma \& Amit Parkash Srivastava, Distribution pattern of HCV genotypes \& its association with viral load, Indian J Med Res 133, March 2011, pp 326-331

[20] Homie Razavi ,Erin Gower, Sarah Hindman, Chris Estes, Global distribution of HCV genotypes, Centre for Disease analysis, Louisville, Colorado, USA, 2013 Nov.

[21] Pouillot R, Lachenal G, Pybus OG, Rousset D, Njouom R Variable epidemic histories of hepatitis C virus genotype 2 infection in West Africa and Cameroon. Infect Genet Evol 2008; $8: 676-81$.

[22] Albrecht Ernst, Hepatitis Central (http://www.hepatitiscentral.com/hepatitis-c/what-is-viral-load.html?ssrc=left sidebar)

[23] Abraham R, Ramakrishna B, Balekuduru A, Daniel HD, 31. Abraham P, Eapen CE, et al. Clinicopath ological features and genotype distribution in patients with hepatitis $\mathrm{C}$ virus chronic liver disease. Indian J Gastroenterol 2009; $28: 53-8$. 